sections. The movement should be kept smooth at all times and the entire mechanism carefully screened from dust. The blades must be kept sharpened to an exact edge, that is, until under fifty diameters of magnification the detectable flaws are negligible.

In cutting, the micro adjustment is set for a 0.03 mm. cut, the action is started slowly, the cut off "specimen" being guided with the finger tip or a bit of card to prevent curling. A good start being assured, the finish of the cut is made in a quick, steady manner. About ten or twenty of such cuts are collected and a few good ones selected for mounting with the aid of a pocket microscope and a small pair of tweezers. The specimens are then mounted on the usual micro slides in Canada balsam diluted with xylot.

Photomicrographs of such sections are easy to make, the best results being obtained by the use of orthochromatic plates with a yellow filter. In the present case, Standard Orthonon plates were used with the Wratten $G$ filter, normal development adjusted to obtain considerable contrast being employed. In some cases the illumination of the camera system was totally direct so that the photographs were taken by light transmitted through the specimen, while in other cases the lighting was partially transmited and partially reflected from the surface of the paper.

Some of the results obtained are shown in the illustrations. Fig. I, C, shows the way in which the mark of the pen carrying India ink penetrates the paper. Fig. III, "Lily of the Valley" paper, from Brazil, shows the long plant fibers. Figs. V and VI are sections through a Velox print: this photograph was taken by transmitted light so that we see on it first the transparent emulsion layer, only about $6 \mu$ thick, then the baryta substratum, which is white by reflected light but absorbs the transmitted light and so appears black, and then finally the paper stock itself.

Eastman Kobak Company

ROCHESTEK, NHW YoRK

\section{A PHOTOMETER FOR THE MEASUREMENT OF THE TRANSLUCENT EFFECT OF PAPER}

\section{BY C. FRANK SAMMET}

Received July 3, 1917

In a previous publication ${ }^{2}$ a new method was explained for the measurement of the translucent effect of paper. The instrument therein described, however, is somewhat complicated and expensive and has not proven entirely practical for extensive use.

A much simpler instrument has been devised for industrial use which meets the necessities of small cost of construction and easy manipulation, and has the added advantages of being sensitive to very small differences in translucent effects. It gives strictly comparable results, although perhaps not absolute values.

The principle of the method is that used in making photometric measurements. Two movable standard white backgrounds are mounted on a track (see Fig. 1). In order to avoid surface glare they are inclined from

s U. S. Dept. Agr., Bureau of Chetnistry, Circ. 96, 1912. the perpendicular at an angle of $30^{\circ}$ toward the source of illumination which is placed between and slightly below them. The distances of the backgrounds from the zero point over the source of illumination are read on scales engraved on the track, the scales reading in millimeters from o to 300 . The centers

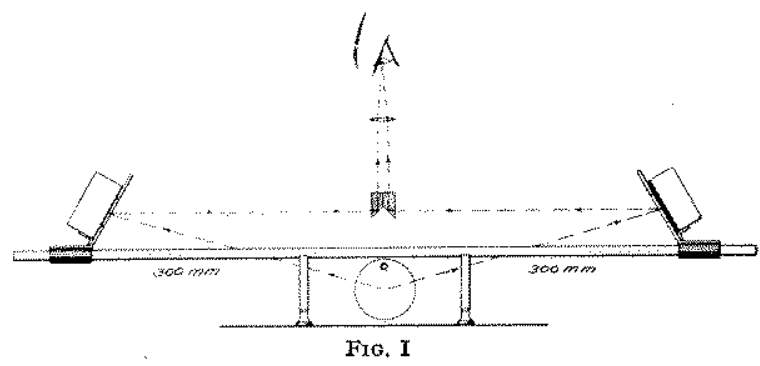

of the areas reflected from the backgrounds should come directly over the $300 \mathrm{~mm}$. marks when the backgrounds are at the ends of the scales. Above the light and the zero point is supported a specially constructed prism and eyepiece so placed as to reflect the surfaces of the backgrounds into adjacent fields. A LummerBrodhum prism is more satisfactory, as it eliminates the dividing line between the fields.

The instrument is set by placing the right-hand block at the $300 \mathrm{~mm}$. mark. The left-hand block is then moved until a position is found where the fields appear matched in luminosity. Five readings should be made to determine the average position. This average reading may be considered constant for any set of papers, provided the position of the light remains unchanged. The left-hand block is then locked in this position.

A single sheet of paper of which the translucent effect is to be measured is then placed over the lefthand block. Another piece is placed over the other block with black velvet between. The black velvet absorbs practically all of the light which the paper transmits, thus allowing only the light from the surface of the paper to reach the corresponding field in

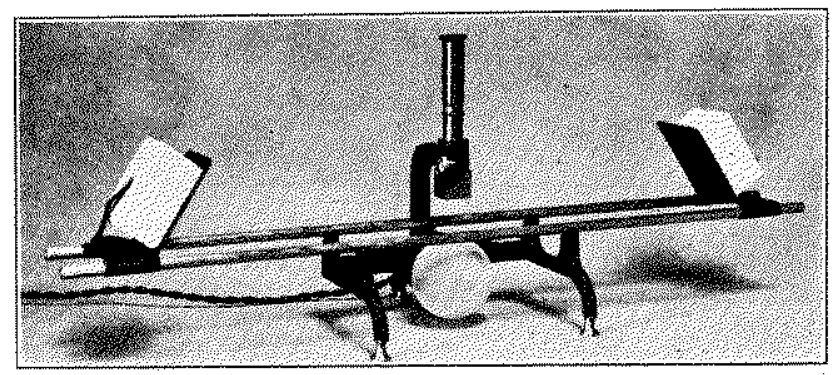

FIG. II

the eyepiece. In conseguence this field is the darker since the other is illuminated by the light reflected from the surface of the paper plus that reflected by the standard white background. When the former block has been advanced toward the light it becomes brighter and finally a position is reached where the fields appear matched. The distance this block bas

3 Black velvet is sufficienty black and the fresh surfaces of the trag nesium carbonate blacks sufficiently white for the sensitiveness of the instrument to cone far within the distinction of differences of translucent effect desired by practical workers. 
been moved is an expression of an amount of light transmitted by the paper to the velvet and then $a b-$ sorbed. This scale reading furnishes a basis for expressing the translucent effect of paper since this effect is dependent upon the light transmitted.

The essential construction of the instrument is shown in the photograph. It must be used in a darkened room and for illumination a frosted roo-watt stereopticon bulb (Mazda) is preferable, as it gives a centralized light. One of materially more watts is too brilliant for accurate work.

The character of results obtained is shown in Table $I$, in which the papers are arranged in the order of translucent effect to the naked eye, and the original and check scale readings and the percentages of translucent effects are recorded.

\begin{tabular}{|c|c|c|c|}
\hline \multicolumn{4}{|c|}{ TABLE I--RESUITS OBTAINED } \\
\hline $\begin{array}{l}\text { Arranged by } \\
\text { Naked Eye }\end{array}$ & $\begin{array}{c}\text { 1st } 5 \text { Readings } \\
\text { Mm. }\end{array}$ & $\begin{array}{c}\text { 2nd } 5 \text { Readings } \\
\mathrm{Mm} .\end{array}$ & $\begin{array}{c}1100\left(1-b^{2} / a^{2}\right) \\
\text { Per cent }\end{array}$ \\
\hline 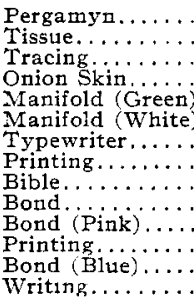 & 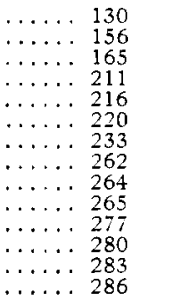 & $\begin{array}{l}129 \\
155 \\
165 \\
213 \\
218 \\
222 \\
235 \\
265 \\
265 \\
265 \\
277 \\
278 \\
283 \\
288\end{array}$ & $\begin{array}{r}81.4 \\
73.1 \\
69.7 \\
50.1 \\
47.7 \\
45.7 \\
39.1 \\
22.8 \\
22.3 \\
22.0 \\
14.7 \\
13.5 \\
11.0 \\
9.5\end{array}$ \\
\hline
\end{tabular}

It is difficult for the naked eye to distinguish between green manifold and white manifold, and also between pink bond and printing. The instrument, however, places them with greater certainty. The order by the naked eye was confirmed by three independent observers.

The backgrounds of magnesium carbonate blocks give very satisfactory smooth, clean, reproducible white surfaces. Only a small area of paper should be exposed since it can be more readily held in close contact with the surface of the block or the black velvet, thus aiding greatly the sensitiveness of the instrument. The blocks must move freely on the tracks for ease of manipulation and accuracy.

Since the intensity of light varies inversely as the square of the distance from the luminous point, the reading, on any paper, substituted in the formula IoO( $\left.I-\frac{b_{2}}{a_{2}}\right)$ gives a value for comparison of the approximate percentage loss of light due to absorption by the black velvet. In the formula, $a$ is the total scale reading and $b$ is the distance that the block is removed from zero.

The prisms of the eyepiece are cut at $4 \Sigma^{\circ}$ angles to reflect adjacent fields and the eyepiece is long to permit the comparisons to be made with the least fatigue. A collar of metal or cardboard may be placed on the eyepiece to shade the eyes from the light of the bulb. A strip may be similarly placed across the track directly over the bulb, or, the instrument may be constructed with the eyepiece horizontal.

In the measurement of the translucent effect of the paper an exact match of color cannot be realized as there is a difference due to the absorption of light by the black velvet. This difficulty is overcome by making the comparisons through a colored glass, either green or brown, placed on the eyepiece.

A colored paper should always be matched through a glass of its predominating hue.

When experience is gained in judging the luminosity match, rather than the color, the method and instrument give results which are satisfactory for all industrial purposes. The instrument should prove practical because of its sensitiveness, low cost, and ease of manipulation over other instruments.

Crane \& COMPANY

Dalton, Mass.

\section{A PRACTICAL REVISION OF THE COBALTI-NITRITE METHOD FOR THE DETERMINATION OF POTASH}

BY R. C. HAFF ${ }^{1}$ AND E. H. SCHWARTZ 1 Recejved July 9. 1917

Some years ago, there appeared in THIS JoLRAAL2 the method for the determination of potash by the use of cobalti-nitrite.

About a year ago, when the Security Cement \& Lime Company began actual operations with their new treater plant with the idea of collecting and selling the dust on account of its high content of water-soluble potash, we were called upon to make a very large number of determinations for potash, not oniy on our own materials but on many other cement and foreign. materials as well.

Since many of these determinations, on which total potash was also required, were made along research lines, mainly, the more laborious and very tedious J. Lawrence Smith method, while it proved very satisfactory as to accuracy of results, was found to be quite impracticable, due to the large laboratory force required and the time consumed in getting our final results.

Tpon receipt of information that the cobalti-nitrite method was employed in the laboratories of the Western Precipitation Company, at Los Angeles, Cal., and in those of Mr. Charles Catlett, at Staunton, Va, we decided to attempt to employ it at Security with the idea of perfecting it in a more uniform laboratory routine, providing we could rely upon the results to check satisfactorily those obtained when employing the recognized Official methods.

The early work with this method required a very great number of duplicate determinations on all grades of material, and particular stress was laid upon the accuracy and reliability of "total potash" results, since all duplicate results on raw material and clinker, in particular, had to be accurate within 0.02 per cent $\mathrm{K}_{2} \mathrm{O}$.

This method has been employed in our laboratory at Security for about nine months and has been found to give most satisfactory results on "total potash" when checked against the J. Lawrence Smith method and on "water-soluble potash" when checked against the Official methods employed and recommended by the American Official Agricultural Chemists.

1 Chief Chemist and Assistant Chemist, respectively, for the Security Cement and Lime Co., Hagerstown. Md.

2 This Journal, 1 (1909), T91. 